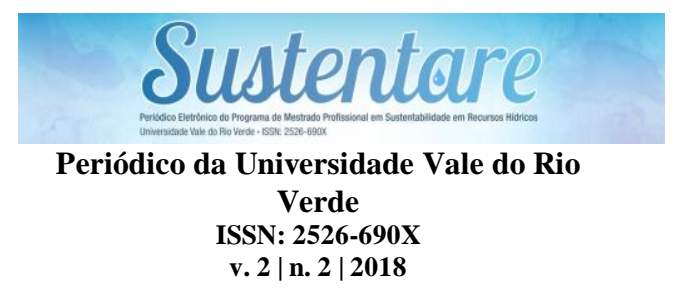

Janaína de Fátima Silva Tostes Graduanda em Engenharia Civil. Unisal-Lorena- SP. janainatostes@outlook.com

Minella Alves Martins Doutora em Ciência do Sistema Terrestre Professora do Departamento de Engenharia. Unisal-Lorena- SP. minella.martins@lo.unisal.br

\section{ANÁLISE DE PRECIPITAÇÃO E SUAS \\ CONSEQUÊNCIAS NO LOTEAMENTO JARDIM VISTA ALEGRE, GUARATIGUETÁ/SP E MEDIDAS DE ADAPTAÇÃO PARA MINIMIZAR IMPACTOS FUTUROS}

Resumo: A cidade de Guaratinguetá - SP apresenta um histórico significativo de alagamentos, especificamente no loteamento Vista Alegre, trazendo prejuízos a população residente na região. De modo geral, o município teve seu processo de urbanização às margens do Rio Paraíba do Sul, portanto está localizado em uma região de fundo de vale, fator que propicia maiores chances de alagamentos. Objetivou-se com este estudo a análise da influência da precipitação intensa nas ocorrências de alagamentos no futuro e, a partir disso, propor soluções sustentáveis para o controle de impactos. Para realização do estudo, foram analisados registros históricos de ocorrências de alagamentos nos últimos 05 (cinco) anos, juntamente com a análise de séries históricas de precipitações intensas assim como dados do Modelo de Projeção Climática Eta-Hadgem, cenário RCP8.5 (2020-2050). Verificou-se que os acumulados mensais de precipitação irão diminuir no futuro. No entanto, a intensidade de precipitação deve aumentar. Dessa forma, medidas estruturais e não estruturais são sugeridas para minimizar futuros impactos.

Palavras-chave: Alagamentos. Precipitação. Drenagem. Adaptação.

\section{ANALYSIS OF PRECIPITATION AND THEIR CONSEQUENCES IN THE GARDEN VISTA ALEGRE, GUARATIGUETÁ / SP AND ADAPTATION MEASURES TO MINIMIZE FUTURE IMPACTS}


precipitation intensity should increase. Thus, structural and non-structural measures are suggested to minimize future impacts.

Keywords: Floodplain. Precipitation. Drainage. Adaptation.

Recebido em: 02/11/2018 - Aprovado em: 03/12/2018 - Disponibilizado em: 11/12/2018

\section{INTRODUÇÃO}

De modo geral, nos centros urbanos e áreas de maior aglomeração populacional cada vez mais é comum ver ocorrências de alagamentos que causam prejuízos ambientais e, principalmente, socioeconômicos para as comunidades das regiões atingidas. Estes alagamentos são fortemente associados às chuvas de alta intensidade. Inferir isso não é uma conclusão totalmente errada, entretanto deve-se considerar que não é a chuva por si só que causa essas ocorrências, mas sim a soma da mesma com o crescimento e desenvolvimento do espaço urbano sem a devida preparação para que esse volume de água oriundo das chuvas seja escoado e direcionado, o que potencializa a gravidade da ocorrência dos desastres.

Nos casos de fundos de vale, a possibilidade de ocorrência de alagamentos está associada com o escoamento superficial das águas precipitadas que convergem para estes locais. A topografia tem forte influência nos caminhos do escoamento superficial, uma vez que, as águas escoam superficialmente sobre a ação da gravidade (SCHUELER; MAHLER, 2007). Além disso, o crescimento urbano causa a diminuição das áreas que permitem a infiltração de água devido a constante impermeabilização do solo e, somado a baixa eficiência dos sistemas de drenagem e captação de águas pluviais, causa o aumento do volume de água que atinge as áreas de relevo mais baixo e são justamente estas áreas que sofrem as principais ocorrências de alagamentos e tem que lidar com as suas consequências.

No caso de Guaratinguetá, no interior do estado de São Paulo, eventos de alagamentos são frequentes. Por exemplo, os eventos de alagamento no loteamento Jardim Vista Alegre. De modo geral, é evidente que a ocorrência desses fenômenos se dá devido à ineficiência da rede de drenagem e, também, à alguns fatores que agravam esses casos, tendo como exemplo o entupimento de canais de escoamento devido ao acúmulo de lixo e, também, a impermeabilização do solo e sua ocupação irregular. Em consequência, 
são ocasionados diversos danos à domicílios e comércios além de ferimentos, perdas humanas e transmissões de doenças.

Dessa forma, é possível depreender que eventos de alagamentos são favorecidos por causas naturais, como por exemplo, a localização geográfica e a topografia do local, além de fatores como a ineficiência da drenagem pluvial urbana. Entretanto, o aumento da intensidade das chuvas vem a ultrapassar o limite de captação das redes de drenagem. Relatórios publicados pelo Painel Intergovernamental de Mudanças Climáticas (IPCC, 2014) têm mostrado que eventos de chuvas intensas tendem a aumentar no futuro em decorrência de alterações no clima.

Caso as projeções do IPCC venham a se confirmar, os prejuízos podem ser ainda maiores, tanto do ponto de vista social quanto econômico e ambiental. Pensando em minimizar os impactos futuros causados por eventos como os de alagamento, muitas cidades vêm se preparando com ações de mitigação e propondo medidas de adaptação. O primeiro passo para efetuar um melhor planejamento das cidades é conhecer como eventos que impactam a sociedade irão ocorrer no futuro.

\section{REFERENCIAL TEÓRICO}

\section{Desastres Naturais}

De acordo com Freitas (2014), um desastre natural resulta da combinação de quatro fatores significativos para a população, sendo estes a ocorrência de uma ameaça natural, uma população exposta, as condições de vulnerabilidade social e ambiental desta população e insuficientes capacidades ou medidas para reduzir os potenciais riscos e danos.

Segundo Atlas Brasileiro de Desastres Naturais (CEPED, 2013), nas últimas décadas os desastres naturais estão presentes no cotidiano da população, entretanto há um aumento considerável não só na frequência e intensidade, mas também nos impactos gerados, ocasionando danos e prejuízos cada vez mais intensos. O referido Atlas expõe que durante o período de 1990 a 2000 ocorreram 38.996 desastres, divididos em 8.515 na década de 1990 e 21.741 na década de 2000 e, apresenta ainda, que em apenas no período de 2010 a 2012 houve um aumento de $22 \%$ em relação a este número.

De acordo com a Codificação Brasileira de Desastres - COBRADE (BRASIL, 2012), os desastres naturais são classificados em cinco tipos distintos. O 
primeiro deles é denominado desastre natural geológico, o qual se subdivide em terremoto, emanação vulcânica, movimento de massa e erosão. Em seguida, tem-se os desastres hidrológicos que são subdivididos em inundações, enxurradas e alagamentos. O próximo item abordado é denominado desastre meteorológico, o qual é fragmentado em sistemas de grande escala ou escala regional, tempestades e temperaturas extremas. Tem-se também o desastre climatológico que se resume em secas e, por fim, os desastres biológicos subdivididos em epidemias e infestações/pragas.

Além das classificações citadas anteriormente, conforme o Sistema Nacional de Proteção e Defesa CivilSINPDED, os desastres também são classificados quanto à origem, a periodicidade, a evolução e a intensidade. Quanto a origem, são subdivididos em naturais os quais são causados por processos ou fenômenos naturais e em tecnológicos os quais são originados de condições tecnológicas ou industriais, incluindo acidentes, procedimentos perigosos e falhas na infraestrutura ou atividades humanas. Já quanto a periodicidade, os desastres classificam-se em esporádicos que são aqueles que ocorrem raramente com possibilidade limitada de previsão e em cíclicos ou sazonais que são aqueles que ocorrem periodicamente relativos a estações do ano e fenômenos associados. Quanto a evolução, são classificados em súbitos ou de evolução aguda e desastres graduais ou de evolução crônica. E, por fim, quanto a intensidade são classificados em dois níveis, sendo o nível 1 desastres de média intensidade e o nível 2 desastres de grande intensidade.

Conforme Atlas Brasileiro de Desastres Naturais (CEPED, 2013), a região Sul do país é uma área frequentemente afetada por alagamentos, inundações bruscas e graduais, escorregamentos, estiagens, vendavais, tornados, nevoeiros e ressacas. Já em relação a região Centro-Oeste, é possível destacar a variabilidade de temperaturas e chuvas decorrente da transição entre os climas quentes e mesotérmicos. Referente a região Norte, onde predomina o clima equatorial chuvoso, é uma área onde praticamente não há estação seca e possui o maior total pluviométrico do país. A região Nordeste, por sua vez, sofre consequências severas tanto devido as secas quanto por precipitações intensas. Por fim, com relação a região Sudeste, é possível constatar que é uma das áreas que mais sofrem com as adversidades atmosféricas devido à ocupação 
desordenada em áreas de risco, tendo como principais ameaças relacionadas ao tempo e clima, as chuvas intensas, vendavais, granizos, geadas e friagens, secas, baixa umidade do ar e nevoeiros.

De acordo com a Figura 1 é possível observar o aumento de registros de ocorrências de desastres naturais no Brasil no período de 1991 a 2012. Percebe-se pela linha de tendência um aumento significativo de eventos no período analisado.

Figura 1 - Desastres naturais no Brasil

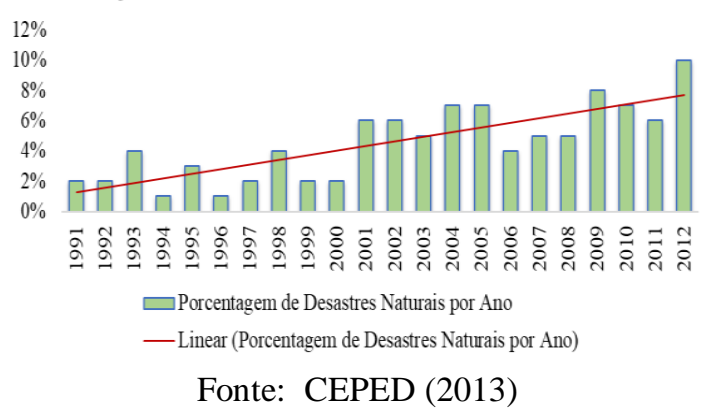

Desastres Naturais hidrológicos

Segundo o Centro Nacional de Monitoramento e Alertas de Desastres Naturais (CEMADEN, 2016), enxurradas podem ser identificadas pelo escoamento superficial concentrado e com alta energia de transporte, que podem estar ou não associadas ao domínio fluvial do rio. De modo geral são causadas por tempestades intensas, podendo arrastar veículos, pessoas, animais e mobílias por vários quilômetros, além de arrancar árvores e destruir edificações. O Cemaden define ainda que inundação é o processo em que ocorre submersão de áreas fora dos limites de um curso de água em zonas que normalmente não se encontram submersas, essa situação é geralmente ocasionada devido chuvas distribuídas e alto volume acumulado na bacia de contribuição. Por fim, o referido Centro de Monitoramento estabelece que os alagamentos são caracterizados pela extrapolação da capacidade de escoamento dos sistemas de drenagem urbana e consecutivo acúmulo de água nas ruas, calçadas e outras infraestruturas urbanas, devido às ocorrências de precipitações intensas e, portanto, os alagamentos não são caracterizados como desastre natural.

\section{Mudanças Climáticas}

De acordo com o IPCC mudanças climáticas são definidas de modo geral como a existência de alterações nas propriedades do clima, tal como mudanças em seu estado médio, desvios-padrão e ocorrência de eventos extremos que ultrapassam os eventos climáticos individuais nas escalas espaciais e temporais os quais persistem durante um longo período. 
Segundo o Painel Brasileiro de Mudanças Climáticas (PBMC, 2016), algumas regiões do Brasil poderão ter seus índices de temperatura e de chuva alterados com o aquecimento global e, com essa mudança nos padrões anuais de chuvas, ocorrerão intensificações de eventos severos.

\section{Urbanização e sua interferência na ocorrência de alagamentos}

De acordo com a Revisão do Plano Municipal Integrado de Saneamento Básico de Guaratinguetá/SP (GUARATINGUETÁ, 2016), a urbanização tem interferência na ocorrência de alagamentos devido ao fato do desenvolvimento populacional das cidades ser desordenado e não planejado, favorecendo a impermeabilização do solo. Dessa forma, a rede de drenagem não planejada não é capaz de suportar e escoar todo o volume das chuvas e, com isso, acaba gerando alagamentos. Além do fator mencionado, vale salientar que existem outros aspectos relevantes quanto à urbanização, como por exemplo, o aumento do volume de lixo produzido e, que muitas vezes, é depositado em locais impróprios como os canais de drenagem e, com isso, gera entupimentos $\mathrm{e}$ consequentes alagamentos.
Em relação ao processo de urbanização, é de extrema importância considerar como elemento causador de alagamentos, a ocupação das áreas as quais antes eram utilizadas, de forma natural, para escoamento das águas das chuvas e que, consequentemente, com o aumento no número de construções, passa a impossibilitar que a água seja drenada.

\section{Cidades Adaptadas}

As Organizações das Nações Unidas (ONU), criou um plano de ações denominado Agenda 2030 para o Desenvolvimento Sustentável, esta Agenda é um conjunto de ações que visa fortalecer a paz universal com mais liberdade. É composta por 17 Objetivos de Desenvolvimento Sustentável e 169 metas, sendo relevante no âmbito do tema deste estudo, o objetivo de número 13 , o qual determina "Ação contra a mudança global do clima" - "Tomar medidas urgentes para combater a mudança do clima e seus impactos".

Conforme Painel Brasileiro de Mudanças Climáticas (PBMC, 2016), devido ao fato de as cidades brasileiras serem vulneráveis às mudanças climáticas é necessário a definição de estratégias de mitigação e adaptação para torná-las resilientes. Neste contexto, é evidente que 
tais alternativas estão relacionadas à limitação do aquecimento global, sendo necessárias intervenções humanas que visem a redução das emissões de gases do efeito estufa.

O referido Plano define ainda que adaptação é o ajustamento nos sistemas naturais ou humanos em resposta a estímulos climáticos reais ou esperados ou a seus efeitos, sendo necessárias medidas de adaptação para o enfrentamento das mudanças climáticas já observadas e futuras.

Existe uma série de opções de adaptação, mas é necessária uma abordagem mais extensa, pois existem barreiras, limites e custos que não são totalmente compreendidos, entretanto, não colocar em prática essas ações custará mais no futuro.

Segundo o IPCC (2014), para a região sudeste tem-se um aumento na temperatura e, referente a precipitação, verifica-se uma redução acentuada das chuvas durante o verão. Dessa forma, haverá como consequência o aumento da frequência de enchentes urbanas e deslizamentos de terra em áreas de encosta, afetando moradores, altas taxas de evaporação e dias secos consecutivos, com mais secura do ar e condições favoráveis ao desequilíbrio hídrico.
O referido Guia expõe ainda as diferenças entre medidas de mitigação e adaptação. As medidas de mitigação têm o intuito de prevenir novas mudanças climáticas, sendo assim, requerem mudanças fundamentais nos sistemas urbanos e energéticos. No entanto, as medidas adaptativas visam a adequação às mudanças climáticas para que as cidades estejam preparadas para suportar eventos extremos.

Segundo Margulis (2017), as medidas de adaptação variam de acordo com cada setor, como por exemplo, estrutura física, social, econômico e institucional. Pode-se citar como exemplos as paredes marítimas e estruturas de proteção costeiras, diques de inundação e alcatrões, armazenamento de água, melhor drenagem, engordamento de praias, abrigos contra inundações e ciclones, códigos de construção, adaptação das infraestruturas viárias e rodoviárias e ajuste de usinas e redes elétricas, irrigação eficiente, armazenamento da água da chuva, sistemas de alerta precoce, insulamento de edifícios, restauração ecológica, reflorestamento, telhados verdes, gestão da pesca, migração assistida ou controlada, corredores ecológicos, gestão adaptativa do uso do solo, sensibilização e integração na educação, mapeamento de perigos e 
vulnerabilidades, previsões mais confiáveis, planos de adaptação baseados na comunidade, conservação do solo e da água, alteração nas práticas de criação de gado e de aquicultura, mudanças culturais agrícolas, incentivos financeiros incluindo impostos e subsídios, pagamentos por serviços ambientais, legislação de zoneamento de terras, padrões de construção, leis para apoiar a redução de riscos de desastre, programas de melhoria urbana, planos diretores de cidades, entre outros.

\section{ÁREA DE ESTUDO}

A região em foco no estudo é o município de Guaratinguetá, localizado na Região Administrativa de São José dos Campos, no Vale do Paraíba. Tem área total de $752,6 \mathrm{Km}^{2}$ e encontra-se nas coordenadas $22^{\circ} 48^{\prime} 45^{\prime \prime} \mathrm{S}$ e $45^{\circ} 11^{\prime} 15^{\prime \prime} \mathrm{W}$, com altitude média $540 \mathrm{~m}$ em relação ao nível do mar. Em relação ao relevo, o município está localizado, ao norte, entre as escarpas e reversos da Serra da Mantiqueira e, ao sul, Serra do Mar, com boa parte de seu território dentro da depressão do Rio Paraíba do Sul. Tem seus afluentes como principais corpos d'água, como o Rio Patury e os Ribeirões dos Lemes, dos Mottas, Gomeral, São Gonçalo, Pilões e Jararaca. Na Figura 1 é apresentado um mapa de localização do município.

Em relação à população da área em estudo, o censo 2010 do Instituto Brasileiro de Geografia e Estatística IBGE, contabilizou uma população de 112.072 habitantes, tendo uma população estimada para 2017 de 120.417 habitantes, exibe ainda uma densidade demográfica de $148,91 \mathrm{hab} / \mathrm{km}^{2}$.

Segundo o Atlas do Desenvolvimento humano no Brasil (2013), a cidade de Guaratinguetá está na $47^{\mathrm{a}}$ posição, tendo Índice de Desenvolvimento Humano Municipal IDHM igual a 0,798, sendo o IDHM renda de 0,764, o IDHM de longevidade de 0,886 e o IDHM de educação de 0,751 .

Conforme Alvares et al. (2014), o município de Guaratinguetá é classificado como clima do tipo Cwa, que apresenta sua estação chuvosa durante o verão e concentrada entre os meses de outubro e março, época esta que coincide com os meses de maior frequência de desastres hidrológicos.

A Figura 2 relaciona a precipitação e temperatura média anual durante os meses do ano. 
Figura 2 - Climatologia município de Guaratinguetá/SP

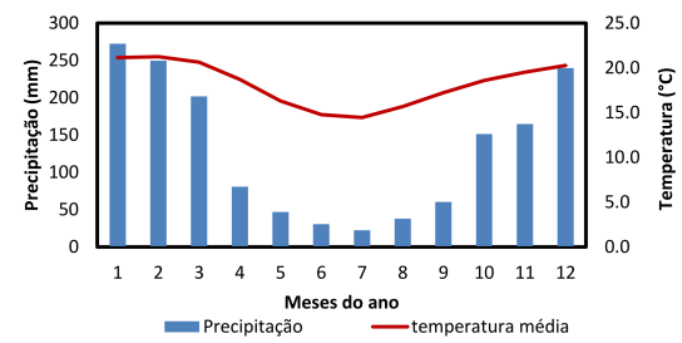

Fonte: Produção das autoras (2018) com base nos dados de Alvares et al. (2014).

\section{MATERIAL E MÉTODOS}

Foram analisados registros históricos de ocorrências de alagamentos nos últimos 05 (cinco) anos no município de Guaratinguetá a fim de estabelecer um limiar de precipitação que fosse causa dos alagamentos. Dados de alagamentos foram obtidos junto à Defesa Civil de Guaratinguetá. Foi feita também uma análise das séries históricas e futuras de precipitação. Os dados de precipitação utilizados no presente trabalho foram obtidos do modelo regional de circulação atmosférica Eta-Hadgem com resolução horizontal de $5 \mathrm{~km}$. Foi considerado o cenário RCP8.5, considerado pelo Painel Global de Mudanças Climáticas (IPCC, 2014) como o cenário mais pessimista de emissão de $\mathrm{CO}_{2}$. O modelo Eta-Hadgem foi previamente avaliado por Lyra et al. (2017). Estes autores relataram bom desempenho do modelo para a região sudeste do Brasil. Sendo assim, as avaliações do presente trabalho se concentraram em uma análise comparativa dos acumulados anuais de precipitação e das frequências de ocorrência de precipitação acima do limiar prédeterminado $(80 \mathrm{~mm} /$ dia $)$ entre o período presente (1975-2005) e o futuro (20202050).Para análise de eventos extremos foi utilizado o índice RX1d, sendo a quantidade máxima de precipitação em um dia, para cada ano.

Os dados utilizados foram obtidos através da plataforma PROJETA Projeções de Mudança do Clima para a América do Sul regionalizadas pelo modelo Eta, disponível no endereço https://projeta.cptec.inpe.br/.

\section{RESULTADOS E DISCUSSÃO}

\section{Análise de séries históricas 1975-2005}

A Figura 3 apresenta os valores referentes à precipitação anual no município de Guaratinguetá no período em estudo. Os dados registrados indicam que os anos que apresentaram maior e menor valor de precipitação foram os anos 1981 e 1975, respectivamente. É possível observar pela linha de tendência, um aumento no volume de precipitação ao longo dos anos. 
Figura 3 - Precipitação Anual no Município de Guaratinguetá no Período de 1975 a 2005.

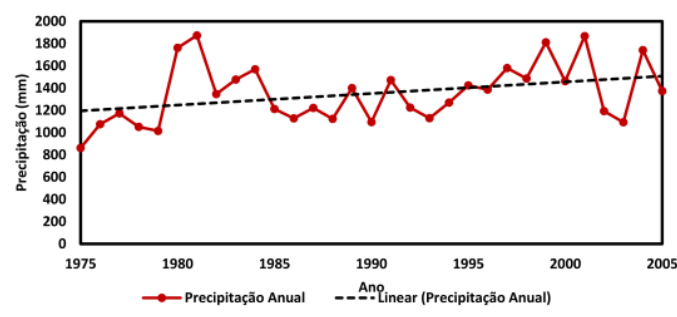

Fonte: Produção das autoras (2018).

Este aumento de precipitação observado, foi também relatado por Valverde et al. (2018) e Oliveira et al. (2018), que mostram que para a região sudeste do Brasil houve um aumento dos totais de precipitação desde a década de 1970. Apesar do aumento nos totais de precipitação, nota-se que a partir do ano 2000 a variação entre anos $\operatorname{secos} \mathrm{e}$ chuvosos é bastante acentuada. Conforme Garcia et al. (2015), para identificação da ocorrência de anos relativamente secos e chuvosos, consideram-se como secos os anos em que a precipitação foi inferior ao percentil $10 \%$ e chuvosos quando a precipitação foi superior ao percentil $90 \%$. Estes autores afirmam ainda que metade dos anos chuvosos foram registrados nos anos de 2000. Segundo Marengo (2014), ao analisar o histórico de ocorrência de eventos extremos, observa-se que nos últimos 30 anos houve um aumento na frequência de chuvas fortes no verão e no inverno do Sul e do Sudeste. Cita como exemplo referente a região Sudeste, a seca de 2014-2015, classificada como a pior dos últimos 80 anos e que a região registrou no ano de 2015 temperaturas de $1^{\circ} \mathrm{C}$ a $2^{\circ} \mathrm{C}$ superiores à média entre os anos 1961 e 1990. Este autor menciona ainda que, o ano de 2014 superou o de 2010 e é o mais quente já registrado desde 1880. De acordo com o Painel Brasileiro de Mudanças Climáticas - PBMC (2016), foram observadas tendências de aumento da precipitação anual no Sudeste, constando $0,6 \mathrm{~mm} /$ dia por 50 anos durante 1950-2008. Verifica-se na Figura 4 os valores médios mensais de precipitação no período em estudo. É possível observar que os meses característicos das estações outono e inverno possuem menores valores médios em relação aos demais, sendo estes os meses maio, junho e julho. $\mathrm{E}$, os meses das estações primavera e verão, a citar novembro, dezembro e janeiro apresentam médias maiores.

Figura 4 - Média, Máximo e Mínimo Precipitação Mensal para o Município de Guaratinguetá no Período de 1975 a 2005.

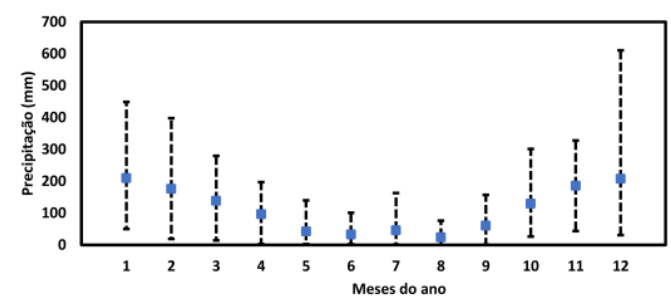

Fonte: Produção das autoras (2018). 
Conforme

apresentado

inicialmente, o limiar obtido como referência é dado por uma precipitação de 80mm em 24 horas, sendo assim, foi realizada uma análise dos dados da variável hidrológica denominada máxima precipitação anual em 1 dia. A partir dos dados exibidos na Figura 5, constatou-se que os valores oscilam entre $33,54 \mathrm{~mm}$ e 146,169 mm, valor que excede o limiar adotado inicialmente.

Figura 5- Máxima precipitação anual em 1 dia

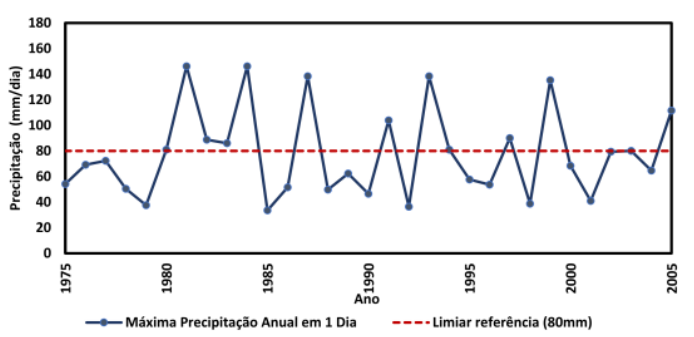

Fonte: Produção das autoras (2018)

É possível observar na Tabela 1 o número de ocorrências que excedem o limiar adotado no período em estudo. Analisando tais dados, é possível verificar as ocorrências com precipitação igual ou superior a $80 \mathrm{~mm} /$ dia no período histórico. Dessa forma, conclui-se que, para o período presente ocorreu 17 eventos de precipitação maiores ou iguais ao limiar de $80 \mathrm{~mm} / \mathrm{dia}$, ou seja, aproximadamente a cada dois anos o município é afetado por uma precipitação maior ou igual ao limiar de precipitação que causou alagamentos e sérios danos ao município.
Tabela 1 - Precipitação diária acima de 80mm

\begin{tabular}{cccc}
\hline Data & Prec & Data & Prec \\
\hline $21 / 02 / 1980$ & 81,0271 & $30 / 10 / 1993$ & 138,339 \\
$21 / 02 / 1981$ & 103,922 & $28 / 01 / 1994$ & 80,9643 \\
$29 / 12 / 1981$ & 146,169 & $21 / 11 / 1997$ & 90,0712 \\
$06 / 11 / 1982$ & 88,7585 & $05 / 02 / 1999$ & 93,5991 \\
$23 / 11 / 1983$ & 86,0343 & $03 / 10 / 1999$ & 135,263 \\
$16 / 12 / 1984$ & 146,169 & $09 / 11 / 1999$ & 90,0654 \\
$26 / 12 / 1984$ & 142,996 & $13 / 12 / 2003$ & 80,0459 \\
$28 / 10 / 1987$ & 138,339 & $14 / 12 / 2005$ & 111,522 \\
$23 / 02 / 1991$ & 103,922 & &
\end{tabular}

Fonte: Produção das autoras (2018).

Projeções de precipitação (2020 A 2050)

Pela análise da Figura 6, nota-se um aumento dos acumulados anuais de precipitação no período 2020-2050.

Figura 6 - Precipitação Anual no Município de Guaratinguetá no Período de 2020 a 2050.

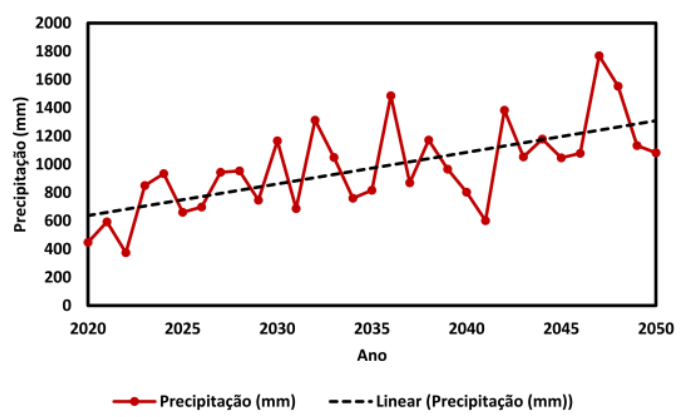

Fonte: Produção das autoras (2018).

Um estudo desenvolvido por Ambrizzi et al. (2017) indicam que, para a cidade de São Paulo, as projeções indicam um aumento dos riscos de desastres naturais, apontando riscos de enchentes, inundações e de deslizamentos, visto que a 
mancha urbana deverá aumentar até 2030. Fazendo um comparativo com os dados de precipitação obtidos para o município de Guaratinguetá, é possível afirmar que tais projeções também podem ser consideradas para a região em estudo, visto que a precipitação tende a aumentar ao longo do período.

Analisando a média mensal do período em estudo, apresentada na Figura 7, verifica-se que o ciclo anual de precipitação mantém o padrão característico do clima presente. No entanto, os valores médios apresentam-se menores que o período histórico (19752005). Por exemplo, enquanto o mês de janeiro e dezembro apresentavam acumulados médios mensais próximos a $200 \mathrm{~mm}$, no período futuro (2020-2050) esses valores ficam em torno de $150 \mathrm{~mm}$. É possível observar também que os valores da máxima e mínima precipitação reduziram, quando comparados ao período histórico (Figura 4).

Figura 7 - Média, Máximo e Mínimo Precipitação Mensal para o Município de Guaratinguetá no Período de 2020a 2050

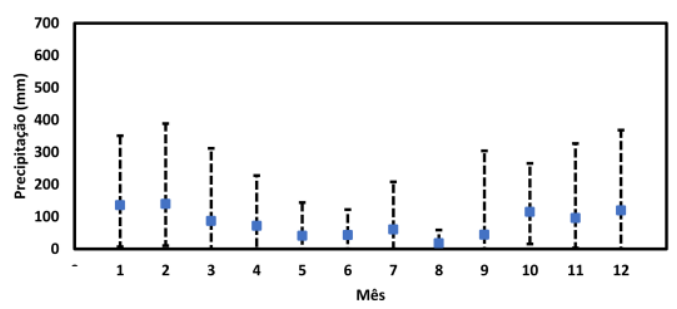

Fonte: Produção das autoras (2018).
Vale salientar que, mesmo a série futura de acumulados anuais de precipitação tendo apresentado uma tendência crescente, os valores de totais anuais não ultrapassam os valores observados para a série histórica, como pode ser observado pela Figura 8, que apresenta o ciclo anual de precipitação para o período histórico (1975-2005, linha vermelha) e período futuro ( 2020-2050, linha azul). Apenas para os meses de junho e julho são esperados um acumulado maior de precipitação no futuro.

Em estudo realizado por Souza e Haddad (2018), referente ao cenário RCP 8.5, verificou-se que as trajetórias das chuvas são mais intensas, pois, de acordo com o autor, além de mais intensas, as anomalias de precipitação previstas são muito mais voláteis no tempo, ou seja, inconstantes. Os autores afirmam que nas décadas de 2020 a 2040, a queda mediana de precipitação no Brasil é equivalente a $5 \%$ e no final do século chega a um número três vezes maior.

Sendo assim, analisando os dados de precipitação para o município de Guaratinguetá, é possível observar na Figura 8, que no período futuro a chuva média mensal diminui em quase todos os meses, exceto maio, junho e julho, quando comparado com o período climatológico de 1975 a 2005. 
Figura 8- Comparativo média mensal nos períodos em estudo.

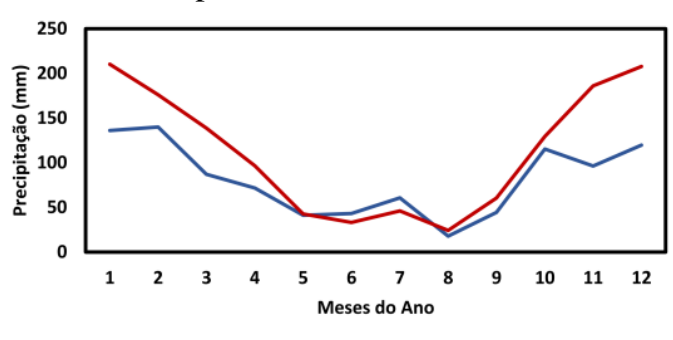

—RCP 8.5 (2020-2050) — Histórico (1975-2005)

Fonte: Produção das autoras (2018).

Foi definido para a análise dos dados, em um período de 24 horas, o valor mínimo de $80 \mathrm{~mm}$. Sendo assim, para o período de 2020 a 2050, constatou-se que os valores variam de $29,05 \mathrm{~mm}$ a 166,40 $\mathrm{mm}$, entretanto, comparando com o período presente, é possível observar um aumento na máxima precipitação anual em $1 \mathrm{dia}$, sendo que para o período passado o maior valor foi 146,169 mm (Figura 5) e para o período futuro o maior valor é equivalente a 166,40 mm (Figura 9), perfazendo uma diferença de aproximadamente $20 \mathrm{~mm}$ a mais, evidenciando o aumento de eventos extremos.

Figura 9 - Máxima Precipitação Anual em 1 Dia.

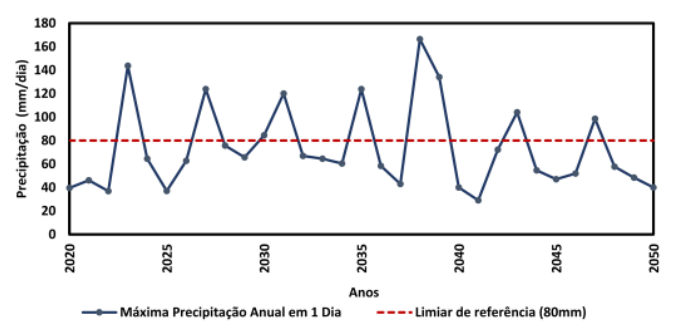

Fonte: Produção das autoras (2018).
Com base nos dados diários de precipitação e relacionando com o limiar considerado como referência (Figura 9), é possível observar na Tabela 2, o número de ocorrências que excedem tal limiar no período de 2020 a 2050.

Tabela 2 - Precipitação acima de $80 \mathrm{~mm}$ no período de 2020 a 2050.

\begin{tabular}{cccc}
\hline Data & Prec & Data & Prec \\
\hline $\mathbf{0 9 / 1 2 / 2 0 2 3}$ & 138,932 & $20 / 10 / 2038$ & 166,408 \\
\hline $\mathbf{1 0 / 1 2 / 2 0 2 3}$ & 143,756 & $03 / 02 / 2039$ & 134,07 \\
\hline $\mathbf{0 1 / 1 0 / 2 0 2 7}$ & 123,809 & $15 / 11 / 2039$ & 84,5669 \\
\hline $\mathbf{1 1 / 1 1 / 2 0 3 0}$ & 84,5649 & $20 / 12 / 2043$ & 104,09 \\
\hline $\mathbf{2 0 / 1 2 / 2 0 3 1}$ & 120,063 & $08 / 03 / 2047$ & 97,5854 \\
\hline $\mathbf{2 3 / 0 1 / 2 0 3 5}$ & 83,0945 & $05 / 11 / 2047$ & 98,5173 \\
\hline $\mathbf{0 5} / \mathbf{0 2} / \mathbf{2 0 3 5}$ & 123,778 & & \\
\hline
\end{tabular}

Fonte: Produção das autoras (2018).

Analisando tais dados é possível verificar, que em um período de 30 anos, têm-se uma projeção de 13 ocorrências de eventos com precipitação acima de $80 \mathrm{~mm}$. $\mathrm{Ou}$ seja, no futuro, aproximadamente a cada 2,5 anos é esperado que município de Guaratinguetá seja afetado por uma precipitação maior ou igual ao limiar de precipitação que causou alagamentos e sérios danos ao município.

De forma geral, os resultados mostraram que a frequência de ocorrência de eventos iguais ou superiores ao limiar de $80 \mathrm{~mm} /$ dia irá diminuir. No entanto, é importante analisar que, ao passo que a 
frequência diminui, os valores máximos aumentam. Enquanto no presente, os valores de máxima precipitação em 1 dia alcançavam $146 \mathrm{~mm}$, no futuro é esperado que estes valores ultrapassem $166 \mathrm{~mm}$.

Valverde e Marengo (2014), analisando os extremos de precipitação para quatro bacias hidrográficas no Brasil, também relataram um aumento da intensidade do RX1d para a bacia do Tocantins e São Francisco, abrangendo grande parte da região sudeste e parte da região Centro-Norte do Brasil. Donat et al. (2016) relataram que as projeções climáticas para o restante do século XXI mostram uma intensificação dos extremos de precipitação e que essa intensificação tem implicações para o risco de inundações à medida que o clima se aquece. Isso sugere que os efeitos serão mais drásticos que hoje, causando diversos prejuízos, no que se refere ao meio ambiente, sociedade e economia.

Portanto, é necessária uma maior preocupação no que tange às medidas de adaptação para minimizar impactos futuros com o intuito de adaptar e preparar as cidades para suportarem tais eventos e, consequentemente, evitar ou amenizar os possíveis danos que podem vir a ocasionar.
Medidas de adaptação para minimizar impactos futuros

Muitos municípios já demostram preocupação quando aos impactos ocasionados por eventos de precipitação. Como exemplo, citam as mobilizações de Lorena, SP e São José dos Campos, SP.

Segundo o Centro Nacional de Monitoramento e Alerta de Desastres Naturais (CEMADEN, 2016), está sendo desenvolvido, juntamente com o município de Lorena/SP, um projeto cujo objetivo é diminuir os riscos de desastres por meio da atuação multidisciplinar e conjunta entre Poder Público, sociedade civil e setor privado. A princípio, as ações se concentram na instalação de 07 (sete) pluviômetros semiautomáticos do Cemaden em escolas municipais de Lorena. Ao longo do ano de 2016 foram realizadas reuniões participativas e oficinas de capacitação com o envolvimento de diferentes secretarias da Prefeitura, sendo essas as secretarias de Educação, Segurança Pública, Saúde e Meio Ambiente além da participação da sociedade civil, como por exemplo, ONGs e empresas. O referido projeto, constituído por ações integradas, de caráter educativo e de mobilização social, proporcionará maior resiliência ao município no que concerne ao monitoramento, alertas e 
respostas aos desastres e, dessa forma, melhorando a qualidade de vida da população, além de favorecer um desenvolvimento econômico sustentável. Portanto, é necessário adquirir essa experiência para que a mesma seja utilizada como referência para que o Cemaden possa expandir a metodologia para outros municípios vulneráveis, com a finalidade de tornarem mais resilientes aos desastres.

Em São José dos Campos, SP a mobilização tem sido em prol da construção de uma Política Municipal de Mitigação e Adaptação às Mudanças Climáticas. O objetivo desse planejamento é implantar um conjunto de diretrizes e ações com o intuito de minimizar a emissão de gases de efeito estufa pelo município e, dessa forma, visando torná-lo mais resiliente aos efeitos das mudanças climáticas. A princípio será elaborado o $1^{\circ}$ Inventário de Emissões de Gases de Efeito Estufa (GEE) e a definição de um Plano de Enfrentamento às Mudanças Climáticas, constituído por metas de redução de gases de efeito estufa, ações e programas prioritários em mitigação e adaptação. Por conseguinte, pretende-se incorporar esses temas em diversas áreas, como planejamento urbano, habitação, saneamento, mobilidade, saúde e desenvolvimento econômico (Prefeitura Municipal de São José dos Campos, 2018).

Medidas estruturais também devem ser pensadas para melhorar a capacidade de resposta a eventos de alagamentos e inundações. Para Pereira (2018), o conceito de Sistema de Drenagem Urbana Sustentável busca aproximar-se o máximo possível do ciclo hidrológico e de suas características antes do processo de urbanização. Para tanto, são realizadas pequenas intervenções ao longo da bacia hidrográfica. $\mathrm{O}$ autor cita alguns elementos constituintes desse modelo de drenagem, como por exemplo, faixas de filtração, valas, bacias de infiltração, bacias de retenção, bacias de detenção, trincheiras de filtração, pavimentos permeáveis e telhados verdes.

Conforme Soares (2018), as bacias de retenção podem ser a céu aberto como reservatórios ao ar livre ou subterrâneas, funcionando como reservatórios de regularização passando a ser um método utilizado em locais de difícil construção de bacias superficiais. $O$ autor cita ainda outra técnica que visa a redução da quantidade de água pluvial escoada, sendo esta, a implantação de telhados verdes. Tal técnica consiste no desenvolvimento de um revestimento vegetal, sendo utilizadas plantas, flores, arbustos ou árvores, ao 
nível da cobertura, podendo ser aplicada em edifícios residenciais, industriais ou comerciais, além de parques de estacionamentos subterrâneos. Por fim, vale ressaltar também, a utilização de sistemas de biorretenção, popularmente conhecidos como jardins de chuva, que são bacias pouco profundas e de pequenas dimensões para captar e filtrar quantidades moderadas de escoamento superficial, utilizando solo e vegetação.

Segundo Souza (2018), os reservatórios de contenção podem contribuir efetivamente para o retardamento dos picos de cheias, devido a vazão proveniente da captação de águas pluviais ser direcionada gradativamente para as galerias de drenagem, reduzindo o risco de alagamentos e inundações.

Tão importante quanto qualquer ação estrutural para adaptar a cidade, fazse necessário conscientizar a população no que se refere a maneira correta de descartar o lixo e conservar os recursos existentes, pois qualquer característica ambiental que possa causar um alagamento é maximizada pelo comportamento da sociedade que vive neste ambiente.

\section{CONCLUSÕES}

A partir dos resultados obtidos, em relação à série histórica, é possível verificar um aumento na intensidade das chuvas para o período de 2020 a 2050. Visto que as tendências dos índices estudados apresentaram um aumento significativo e as cidades não estão preparadas para suportar eventos extremos, é necessário criar medidas de adaptação para obtenção de resultados a curto e médio prazo e, a longo prazo, desenvolver medidas de mitigação para atuarem nas causas das mudanças climáticas e, consequentemente, diminuir a necessidade de medidas adaptativas no futuro.

Um aspecto interessante a ser analisado em trabalho futuros é analisar os dados de precipitação em conjunto com mapas de expansão da mancha urbana e área impermeabilizada do município.

\section{AGRADECIMENTOS}

Os autores agradecem ao Eng. Helvécio Zago e ao Prof. Msc. Mosefran Firmino pelos valiosos comentários que contribuíram para enriquecer o presente trabalho. Agradecem também à Prefeitura Municipal de Guaratinguetá pela disponibilização de dados referentes à área de estudo. 


\section{REFERÊNCIAS}

ALVARES, C. A., STAPE, J. L., SENTELHAS, P. C., MORAES, G. DE, LEONARDO, J., SPAROVEK, G.

Köppen's climate classification map for Brazil. Meteorologische Zeitschrift. v. 22 n.6, p. 711 - 728. 2013.

AMBRIZZI, T.; ARAUJO, M.; FERRAZ, S. E. T.; MORAES, O. Observações e Atribuição de causas da Variabilidade e extremos climáticos. In: Carlos A. Nobre e José A. Marengo. (Org.). Mudanças climáticas em rede: um olhar interdisciplinar. 1ed.São José dos Campos: Canal 6 Editora, v. 1, p. 6996.2017.

Atlas do Desenvolvimento Humano no Brasil. Plataforma de consulta ao Índice de Desenvolvimento Humano Municipal (IDHM). 2010. Disponível em: < http://atlasbrasil.org.br/2013/pt/consulta/> Acesso em: 20/10/2018.

BRASIL. Ministério da Integração Nacional. Instrução Normativa $\mathrm{n}^{\circ} 01$, de 24 de Agosto de 2012 do Ministério da Integração Nacional, 2012. Disponível em: < http://www.mi.gov.br/documents/10157/3 776390/Instru Normativa 01.pdf/8634a6e 3-78cc-422a-aa1d-7312ce7f1055 > .

Acesso em: 10-12-2018.

Centro Nacional de Monitoramento e Alerta de Desastres Naturais CEMADEN. Ameaças Naturais: Enxurradas. 2016. Disponível em:< https://www.cemaden.gov.br/enxurrada/> Acesso em 23-10-2018.

Centro Universitário de Estudos e Pesquisas sobre Desastres - CEPED. Atlas Brasileiro de Desastres Naturais: 1991-2012, 2 ed. Centro Universitário de Estudos e Pesquisas sobre Desastres,
Universidade Federal de Santa Catarina, Florianópolis, 184 pp. 2013.

DONAT, M.G.; LOWRY, A.L.;

ALEXANDER, L.V.; O'GORMAN, P.A.; MAHER, N. More extreme precipitation in the world's dry and wet regions.

Nature Climate Change. V.6, p. 508513. 2016.

FREITAS, C.M.; SILVA, D.R.X.; SENA, A.R.M.; SILVA, E.L.; SALES, L.B.F.; CARVALHO, M.L.; MAZOTO, M.L.; BARCELLOS, C.; COSTA, A.M.; OLIVEIRA, M.L.C.; CORVALÁN, C. Desastres naturais e saúde: uma análise da situação do Brasil. Ciência \& Saúde Coletiva, v.19. n.9. p.3645-3656. 2014.

GARCIA, C.; MARQUES, V.; PEREIRA, P.; POMPEU, C.; OKAWA, C.;

ILDEFONSO, J. Influência da configuração topográfica na ocorrência de alagamentos no município de Maringá, Paraná. Revista Eletrônica em Gestão, Educação e Tecnologia Ambiental. v.19. 2015.

Guaratinguetá. Prefeitura Municipal de Guaratinguetá. Plano Municipal Integrado de Saneamento Básico de Guaratinguetá/SP - Revisão Dezembro de 2016-2040 - elaborado em 2012, aprovado pelo Decreto Municipal n 8.102 de 31 de maio de 2016. Disponível em: < http://guaratingueta.sp.gov.br/wpcontent/uploads/2017/01/Revis\%C3\%A3o -PMISB-Guaratinguet\%C3\%A12016.pdf> Acesso em 24-07-2018.

INTERGOVERNMENTAL PANEL ON CLIMATE CHANGE - IPCC. Climate Change 2014: Synthesis Report. Contribution of Working Groups I, II and III to the Fifth Assessment Report of the Intergovernmental Panel on Climate Change [Core Writing Team, R.K. Pachauri and L.A. Meyer (eds.)]. IPCC, Genova, Switzerland, 151 pp. 2014. 
Disponível em: <

http://www.ipcc.ch/report/ar5/syr $>$.Acesso em 09-04-2018.

LYRA, A., TAVARES, P., CHOU, S.C., SUEIRO, G., DERECZYNSKI, C.P.,

SONDERMANN, M., SILVA, A.,

MARENGO, J., GIAROLLA, A. Climate

change projections over three metropolitan regions in Southeast Brazil using the nonhydrostatic Eta regional climate model at $5-\mathrm{km}$ resolution. Theoretical and

Applied Climatology. v. 132, Issue 1-2, pp 663-682. 2017.

MARENGO, J. O futuro clima do

Brasil. REVISTA USP.São Paulo. n. 103.

p. 25-32. 2014.

MARGULIS, S. Vulnerabilidad y adaptación de las ciudades de América Latina al cambio climático. 2017.

Comisión Económica para América Latina y el Caribe e EUROCLIMA. Santiago de Chile, LC/TS.2017/12, 80p.Disponível em: <

http://www.cepal.org/es/publicaciones/410 41-vulnerabilidad-adaptacion-ciudadesamerica-latinaal-cambio-climatico> Acesso em 13-05-2018.

OLIVEIRA, A. S.; PEREIRA, G. A. RODRIGUES, A.F. MELO NETO, J.O.

Tendências em índices extremos de precipitação e temperatura do ar na cidade de Uberaba, MG. Periódico da

Universidade Vale do Rio Verde. v. 2. n.1. 2018 .

Painel Brasileiro de mudanças Climáticas PBMC. Mudanças Climáticas e

Cidades. Relatório Especial do Painel

Brasileiro de Mudanças Climáticas

[Ribeiro, S.K., Santos, A.S. (Eds.)].

PBMC, COPPE - UFRJ. Rio de Janeiro,

Brasil. 116p. 2016.

PEREIRA, M. J. O. Estudo de implantação de bacias de detenção para mitigação dos efeitos de inundação em
Nova Friburgo/RJ. Tese de Doutorado. Universidade Federal do Rio de Janeiro. 2018.

SCHUELER, A.S.; MAHLER, C.F. Sistema de avaliação para classificar áreas de disposição de resíduos sólidos urbanos visando a remediação e a pós-ocupação. Engenharia sanitária e ambiental.v.13. n.3. p.249-254. 2007.

SOARES, C. J. M. Zoneamento de áreas vulneráveis a inundação e alagamento em Rio Claro-SP, pelo método AHP. Trabalho de conclusão de curso (Engenharia Ambiental) - Universidade Estadual Paulista Júlio de Mesquita Filho, Instituto de Geociências e Ciências Exatas, 2018. Disponível em: <http://hdl.handle.net/11449/157005> Acesso em 20-10-2018.

SOUZA, B. S.; HADDAD, E. A. Mudanças Climáticas no Brasil: Efeitos Sistêmicos sob Cenários de Incerteza. 2018. Disponível em: < https://www.anpec.org.br/encontro/2018/s ubmissao/files I/i11f6f58b30660b2852493df7d2d66c9d50.pdf .> Acesso em 19-09-2018.

SOUZA, R. C. C. de. Método para dimensionamento eficiente de reservatórios de contenção de cheias para a cidade de Curitiba-PR.

Dissertação (Mestrado em Engenharia Civil) - Universidade Tecnológica Federal do Paraná, Curitiba, 2018.

VALVERDE, M. C.; CARSOSO, A.O.; BRAMBILA, R. O padrão de chuvas na região do $A B C$ Paulista: os extremos e seus impactos. Revista Brasileira de Climatologia. v.22. 2018.

VALVERDE, M.C.; MARENGO, J. A. Extreme Rainfall Indices in the Hydrographic Basins of Brazil. Open 
Journal of Modern Hydrology, v.4,

p.10-26. 2014. 